\title{
Which models can be used as a clinical education model in occupational therapy? Introduction of the models: A scoping review study
}

\author{
Marzieh Pashmdarfard ${ }^{1}$, Kamran Soltani Arabshahi ${ }^{2}$, Narges Shafaroodi*1묘 Afsoon Hassani Mehraban $^{1}$, Soroor Parvizi ${ }^{3}$, \\ Kirsti Haracz ${ }^{4}$
}

Received: 18 Jun 2019

Published: 8 Jul 2020

\section{Abstract}

Background: Clinical education is a vital part of occupational therapy education process. High clinical education quality in fieldwork settings leads to higher clinical competency and occupational proficiency. One of the most effective clinical education methods in equalizing the conditions of clinical education to students is the correct use of educational models related to each field of medical sciences. In the field of clinical education, various models have been designed with a specific subject. However, limited research has been done on the introduction of the usability of these models in occupational therapy settings. This study was conducted to determine which models have the potential to be used as clinical education models in occupational therapy.

Methods: A scoping review was conducted and studies published in English between 2000 and 2018 that examined clinical education models were selected.

Results: A total of 8 articles were entered in the review, and a central theme of implementing clinical education models in occupational therapy was determined by thematic analysis. This central theme consisted of 3 categories: (1) evaluative models, (2) acting models, and (3) evaluative/acting models.

Conclusion: Occupational therapists, especially who work as educators should be aware of the different types of clinical education models and try to use these models in clinical education process and minimize the variation of teaching methods in fieldwork settings to promote the clinical education quality. However, more research should be done to improve evidence-based occupational therapy practice in clinical education.

Keywords: Models, Occupational therapy, Education, Clinical practice

Conflicts of Interest: None declared
Funding: None

*This work has been published under CC BY-NC-SA 1.0 license.

Copyright $\odot$ Iran University of Medical Sciences

Cite this article as: Pashmdarfard M, Soltani Arabshahi K, Shafaroodi N, Hassani Mehraban A, Parvizi S, Haracz K. Which models can be used as a clinical education model in occupational therapy? Introduction of the models: A scoping review study. Med J Islam Repub Iran. 2020 (8 Jul);34:76. https://doi.org/10.47176/mjiri.34.76

\section{Introduction}

Occupational therapy is a completely practical and clinical

Corresponding author: Dr Narges Shafaroodi, shafarodi.n@iums.ac.ir

1. Department of Occupational Therapy, School of Rehabilitation Sciences, Iran University of Medical Sciences, Tehran, Iran

2. Center for Educational Research in Medical Science (CERMS), Department of Medical Education, School of Medicine, Iran University of Medical Sciences, Tehran, Iran

3. Nursing Care Research Center, School of Nursing and Midwifery, Center for Educational Research in Medical Science (CERMS), Department of Medical Education, School of Medicine, Iran University of Medical Sciences, Tehran, Iran

4. OT School of Health Sciences, Faculty of Health and Medicine, University of Newcastle, Newcastle, New South Wales, Australia profession in which the therapists develop a strong relation-

\section{$\uparrow$ What is "already known" in this topic:}

Clinical education is an important part of occupational therapists' curriculum. In the field of rehabilitation education, especially occupational therapy, there has not been a definite educational model. Thus, the present study aimed to identify the models with the potential to be used as clinical education models in occupational therapy clinical education settings.

\section{$\rightarrow$ What this article adds:}

Occupational therapists who work as educators should be trained to use the clinical education models to minimize the variation of teaching methods and promote the clinical education quality. Clinical education models can improve the quality of clinical education process, and different types of clinical education models (acting, acting/evaluating, evaluating) can be used in occupational therapy fieldwork education. 
ship with their clients and their caregivers. Theoretical, practical, and clinical processes constitute the framework for teaching in occupational therapy. Therefore, clinical education is an essential part of occupational therapists' curriculum. Also, students should receive theoretical training in occupational therapy in practice and during clinical education (1). Clinical education is a complex process that is influenced by many factors and is also important in medical education (2). In the field of health, clinical education is the most important component that connects the educational environment to the medical environment, increasing the range of information, skills, and abilities of students (1). Clinical education is an essential part of the training of health professionals, including rehabilitation specialists, without which theoretical knowledge will not lead to real therapy. Clinical education is defined as acquisition of professional clinical education skills under the supervision of a trainer or acquisition of clinical education through a clinical-educational model (3). The complexity of learning in the clinical setting has led researchers to examine clinical education in clinical education settings among students from different dimensions (4). In 2010, Abutalebi et al assessed the status of clinical education in medical education and concluded that the overall clinical education level is at the borderline level (50.92). They added that effective clinical education training and evaluation systems should be developed (5). Considering the inadequate efficiency of graduated students, the lack of continuous training for students in some cases (6) and the lack of cooperation of the personnel of the relevant departments in clinical education (4), the need for changes and modifications in clinical education method is felt (1). One of the disadvantages of conventional clinical education and clinical evaluation is uniform application for all field works in different semesters. Therefore, it does not correspond to the clinical experience of students and does not confirm the clinical competence of graduated students (7). Health education system has an important role in the training of skilled specialists in quantitative and qualitative aspects. If the health education system is able to train skilled workers, then the quality of health services will also improve. An educational system can be more efficient when it performs its own tasks of high clinical education quality. Thus, finding ways to improve the quality of educational services, especially clinical education, is of significant importance (6). One of the basic challenges that universities must pay attention to is the development of a coherent educational system for providing desired services and using strategic methods to improve the quality of clinical education services (7). Considering that the educational system contributes to the quality of health care services and the growth of the society, the study of appropriate educational methods, especially clinical education, can help educational professionals to achieve this goal (6). In general, models are used to explain how human behavior and the related factors are performed. Therefore, one of the most effective methods of clinical education to equalize the conditions of clinical education to students is the correct use of educational models, especially clinical education models related to each field of medical sciences (1).
In the field of clinical education, a variety of educational models have been designed with a specific subject. Since the effectiveness of these educational models requires their proper use, so far, in the field of rehabilitation education, especially occupational therapy, no definite educational model has been designed. The methodology of Arksey and O'Malley scoping study (8) was used to determine which models have the potential to be used as clinical education models in occupational therapy clinical education settings.

\section{Methods}

\section{Data collection procedure}

This study was conducted based on limited research. A scoping review was performed through the methodology proposed by Arksey and O'Malley $(8,9)$. This review was done in 5 stages:

1. Definition of the research question;

2. Systematic search;

3. Article selection based on inclusion criteria;

4. Data schema;

5. Summarizing the results (8).

\section{Definition of the research question}

The present study was designed to investigate the models that have the potential to be used as clinical education models for occupational therapy in clinical education settings.

\section{Systematic search}

Search strategy: To search systematically, all the articles related to the clinical education models in the field of medical sciences published from 2000 to 2018 were collected. The whole procedure was performed between December 2017 and March 2018. The CINHAL, psycINFO, MEDline, and EMBASE databases were systematically searched for the articles on the models that had the potential to be used as clinical education models in rehabilitation sciences.

Keywords: The following keywords were used in the process of search strategy: education, model, clinical education, clinical practice, clinical education model, medical sciences, rehabilitation sciences, practical model, medical education, learning, medical students, clinical model, education model, practical teaching model, theory-practice model, medical education model, medical practical teaching model, and medical theory-practice model. In addition, the Boolean operators, such as AND and OR, were used to combine these terms (eg, clinical education AND occupational therapy) and gain more productive findings.

\section{Article selection based on inclusion criteria}

The inclusion criterion was the presence of clinical education models of medical sciences in the articles. Therefore, all retrospective and prospective articles, experimental and semiexperimental studies, observational studies, and qualitative studies conducted on these models were included in this study. On the other hand, those articles which did not cover the clinical education models of medical sciences were excluded from the study (Table 1). 
Table 1. Inclusion and exclusion critera

\begin{tabular}{l} 
Inclusion criteria \\
\hline Related articles with the full-text or abstracts about the clinical \\
education model in English \\
Related articles from 2000 to 2018 \\
Articles related to the clinical education models of medical sciences \\
The availability of full-text articles or abstracts
\end{tabular}

The utility of retrospective and prospective papers, experimental and semi experimental studies, observational studies, and qualitative studies about the clinical education models in medical sciences
Exclusion criteria

Articles (abstract or full-text) that were found in languages other than English.

Articles that had been done before 2000

Articles related to other sciences

Articles related to other concepts of medical sciences, except for clinical education models
The preferred reporting items for systematic reviews and meta-analysis process (PRISMA) was used to sort out the studies which had this inclusion criterion (10). To determine the eligibility of the selected articles for the systematic review, preliminary screening was conducted on article titles, followed by a review of abstracts. If reviewing the abstract of an article did not clarify whether the article was relevant to this study or not, the full-text document of that article was retrieved and reviewed. The first author conducted this phase, and each stage was peerreviewed by other authors.

\section{Data schema}

Charting the data: In this study, the articles were categorized using key items, including, model name, model description, author, publication year, study setting, methodology, participants, and conclusions (8).

Data Collation: The thematic analysis proposed by Brown and Clark (2006) was used for data collection. In this regard, an inductive thematic analysis was done for all the selected articles. To this end, all the studies on the educational models that could be used in occupational therapy were read several times (11). The initial codes were extracted from the texts and entered into an excel spreadsheet. The themes were identified by grouping the related codes; then, the overarching themes were detected. Finally, the themes were refined through the comparison of the obtained themes with the original codes and articles. One of the authors performed this phase and other authors peer-reviewed each stage.

\section{Results}

In the search strategy phase, 2 researchers selected articles on an individual basis. The agreement rate between the 2 researchers was approximately $82 \%$, which was quite satisfactory. A total of 50 articles were found after searching in the data resources. However, 23 articles were removed because of duplicability and 8 due to their nonEnglish language. The remaining 19 articles were screened again, among which 14 articles met the eligibility criterion. After a more profound review of the 14 articles, 6 were excluded, as they were associated with assessment scales in clinical education settings rather than with clinical education models. Ultimately, 8 articles were sorted out for further analysis (Fig. 1). The findings of each study are presented in Table 2.

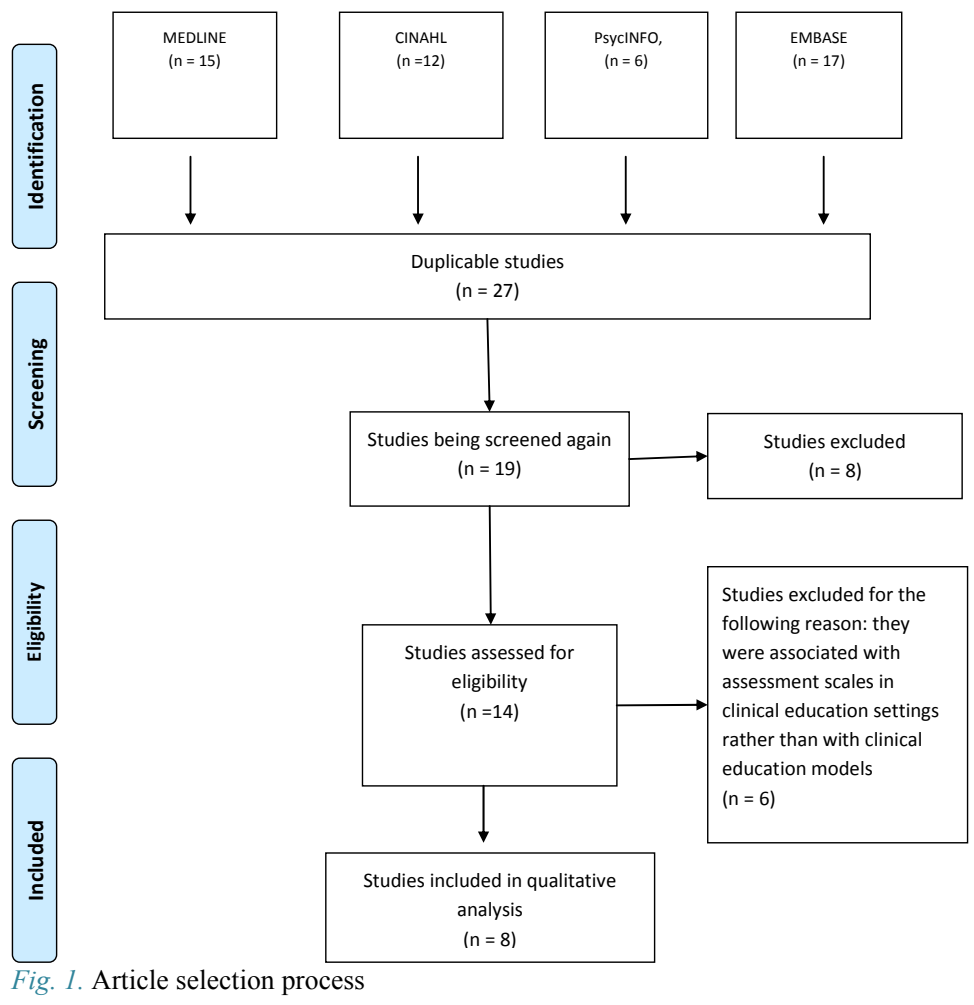




\begin{tabular}{|c|c|c|c|c|c|c|}
\hline $\begin{array}{l}\bar{d} \\
\frac{0}{0} \\
\Sigma\end{array}$ & About the models & 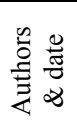 & 总 & 忌 & 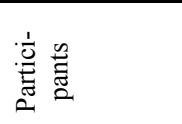 & 卢 き \\
\hline 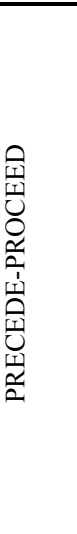 & $\begin{array}{l}\text { This model was first developed by Lawrence W. Green, et } \\
\text { al (1974). This model is influenced by both individual and } \\
\text { environmental factors and has } 2 \text { distinct parts. First is an } \\
\text { "educational diagnosis" - PRECEDE, an acronym for Pre- } \\
\text { disposing, Reinforcing and Enabling Constructs in Educa- } \\
\text { tional Diagnosis and Evaluation. Second is an "ecological } \\
\text { diagnosis" - PROCEED, for Policy, Regulatory, and Organ- } \\
\text { izational Constructs in Educational and Environmental } \\
\text { Development. This model consists of four planning phases, } \\
\text { one implementation phase, and } 3 \text { evaluation phases. }\end{array}$ & 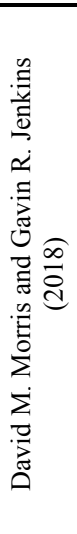 & 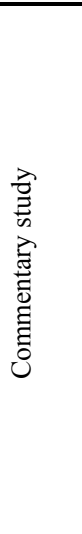 & 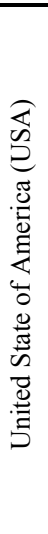 & 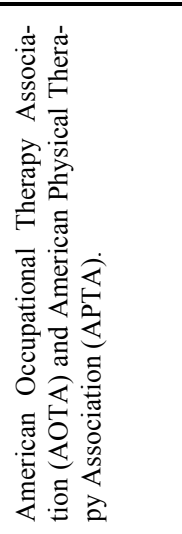 & 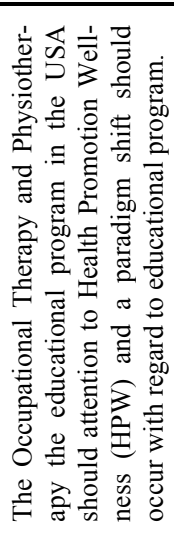 \\
\hline 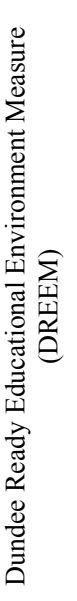 & $\begin{array}{l}\text { DREEM is an international model which was developed by } \\
\text { Sue Roff et al (1997). To provide feedback on strengths and } \\
\text { weaknesses of the educational environment in particular } \\
\text { educational institutions. This model is an assessment tools } \\
\text { model which consists of } 5 \text { dimensions and assesses 1- } \\
\text { teaching qualities, 2- characteristics of teachers, } 3 \text { - in- } \\
\text { volvement, 4- affiliation and 5- school climate or general } \\
\text { affect. }\end{array}$ & 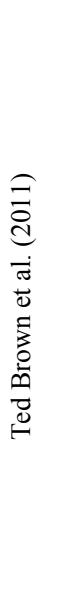 & 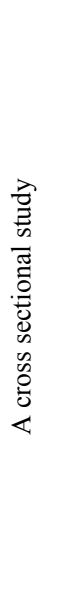 & 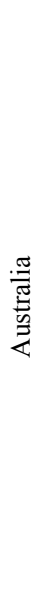 & 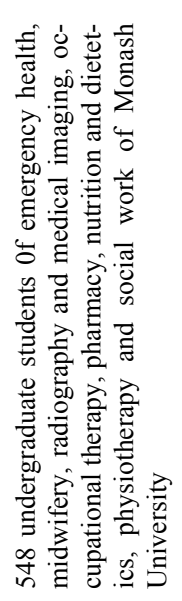 & 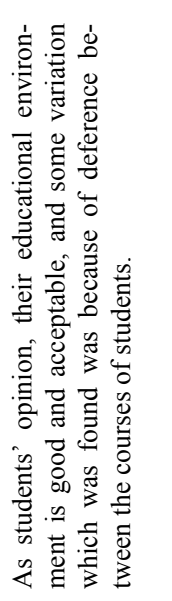 \\
\hline 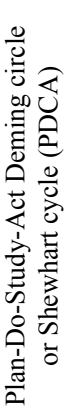 & $\begin{array}{l}\text { PDCA circle was developed by W. Edwards Deming (1993) } \\
\text { and Walter A. Shewhart et al (1986). It is the overall quality } \\
\text { management, including Plan, Do, Check and Act. This } \\
\text { circle is a common method among nurses for promoting } \\
\text { clinical nursing quality. The } 4 \text { phases are: } \\
\text { Plan: What is needed } \\
\text { Do: It } \\
\text { Check: That it works } \\
\text { Act: To correct any problems or improve performance }\end{array}$ & 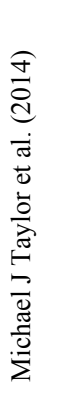 & 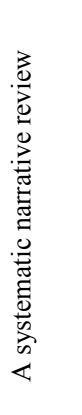 & 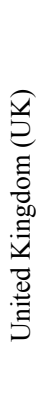 & $\begin{array}{l}\stackrel{n}{0} \\
\stackrel{\mathscr{E}}{E} \\
\infty \\
n\end{array}$ & 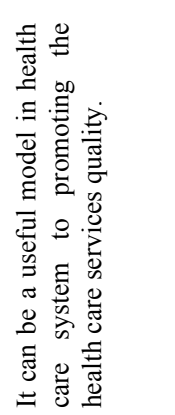 \\
\hline
\end{tabular}

\section{Descriptive analysis}

The publication dates of the selected articles $(n=6)$ ranged from 2000 to 2018 . Most of these articles $(n=4)$ were published between 2011 and 2018, and only 2 were published between 2000 and 2009. Most of the studies were conducted in the US $(n=4)$ and were published from 2013 to 2018, and articles conducted in the UK $(\mathrm{n}=1)$, Canada $(\mathrm{n}=1)$, Australia $(\mathrm{n}=1)$, and Thailand $(\mathrm{n}=1)$ were published in 2014, 2009, 2011, and 2000 respectively. Interestingly, among the 4 articles conducted in the US, 1 was published in 2013, 1 in 2017, and 1 in 2018, which suggests that clinical education models have recently gained importance in the clinical education settings of occupational therapy in the US. The most frequently reported findings of these articles have proved the utility of implementing clinical education models for teaching methods, evaluation methods, relationships among students, teachers, and clients, curriculum development or revision, and the improvement of clinical education quality in occupational therapy (12-14).

\section{Thematic analysis}

In the thematic analysis of the studies, a major theme was detected for implementing the models as clinical education models in occupational therapy. Within this theme, 3 subcategories of the models were identified as follows: evaluative models; acting models; and acting /evaluative models. The alignment of these concepts is provided in Table 3. 


\begin{tabular}{|c|c|c|c|c|c|c|}
\hline $\begin{array}{l}\bar{d} \\
\frac{\delta}{\Sigma}\end{array}$ & About the models & 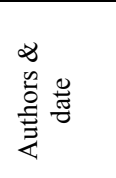 & 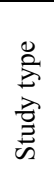 & $\begin{array}{l}\vec{E} \\
\text { 㝵 }\end{array}$ & 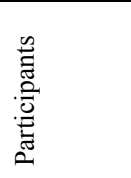 & $\begin{array}{l}\mathscr{\Xi} \\
\tilde{0} \\
0 \\
0\end{array}$ \\
\hline 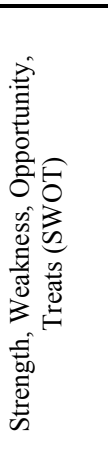 & $\begin{array}{l}\text { SWOT analysis (or SWOT matrix) was developed by Al- } \\
\text { bert Humphrey et al (1960) and is a strategic planning } \\
\text { technique used to help a person or organization. It identifies } \\
\text { the strengths (internal factor), weaknesses (internal fac- } \\
\text { tor), opportunities (external factor), and threats (external } \\
\text { factor). }\end{array}$ & 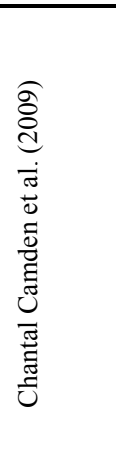 & 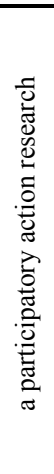 & 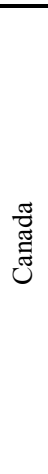 & 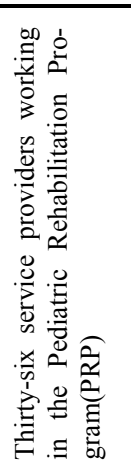 & 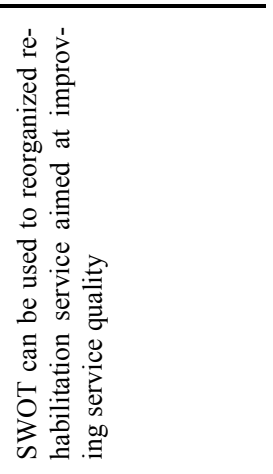 \\
\hline 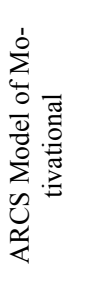 & $\begin{array}{l}\text { The ARCS model is an approach that focuses on the moti- } \\
\text { vational aspects of learning environment which was devel- } \\
\text { oped by John Keller in } 1983 \text {. According to John Keller's } \\
\text { ARCS Model of Motivational Design Theories, there are } 4 \\
\text { steps for promoting and sustaining motivation in the learn- } \\
\text { ing process: attention, relevance, confidence, and satisfac- } \\
\text { tion (ARCS). }\end{array}$ & 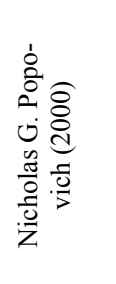 & 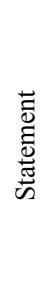 & 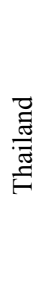 & , & 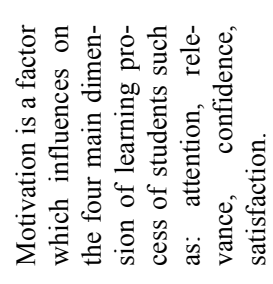 \\
\hline 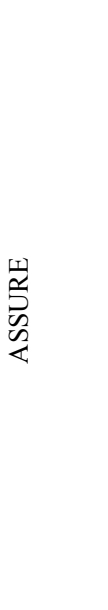 & $\begin{array}{l}\text { The ASSURE model is an ISD (Instructional Systems De- } \\
\text { sign) process that was modified to be used by teachers in } \\
\text { regular classrooms and was developed by Heinich, Mo- } \\
\text { lenda, Russell, and Smaldino (1999). Teachers and trainers } \\
\text { can use this model to design and develop the most appropri- } \\
\text { ate learning environment for their students. You can use } \\
\text { this process in writing your lesson plans and in improving } \\
\text { teaching and learning. A-Analyze learners, S - State } \\
\text { standards \& objectives, S - Select strategies, technology, } \\
\text { media \& materials, U - Utilize technology, media \& mate- } \\
\text { rials, R - Require learner participation, E - Evaluate \& } \\
\text { revise. }\end{array}$ & 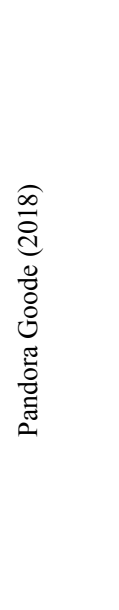 & 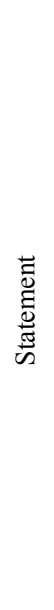 & $\underset{ٌ}{\overleftrightarrow{ら}}$ & & 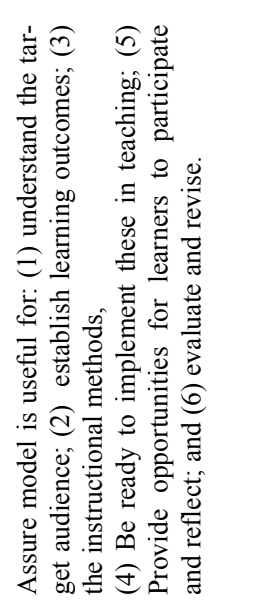 \\
\hline & 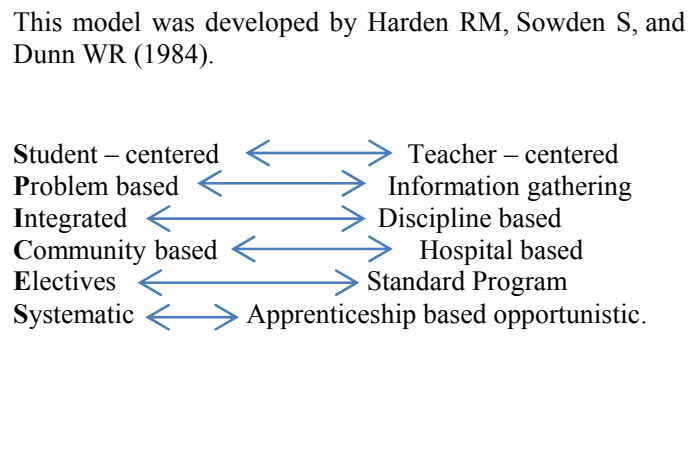 & 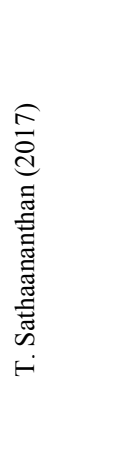 & 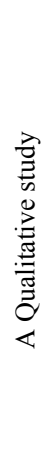 & 岕 & 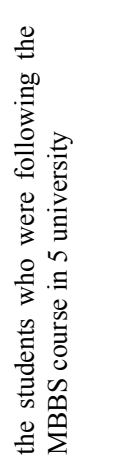 & 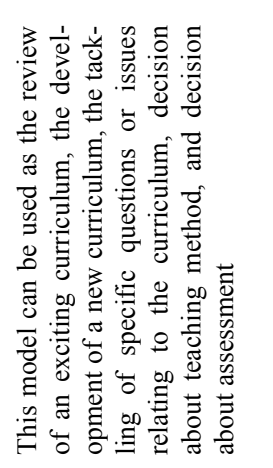 \\
\hline 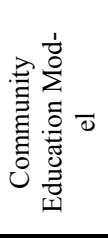 & $\begin{array}{l}\text { Also known as community-based education or community } \\
\text { learning \& development, is an organization's programs to } \\
\text { promote learning and social development work with indi- } \\
\text { viduals and groups in their communities using a range of } \\
\text { formal and informal methods. This model was developed by } \\
\text { Larry Horyna and Larry Decker for the National Coalition } \\
\text { for Community Education (1991). }\end{array}$ & 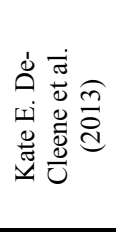 & 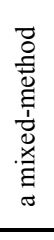 & 芯 & 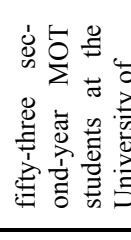 & 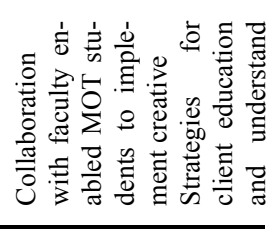 \\
\hline
\end{tabular}


Which models can be used as clinical education models in occupational therapy?

\begin{tabular}{|c|c|c|c|}
\hline $\begin{array}{l}\text { Central } \\
\text { theme }\end{array}$ & Categories & Subcategories & Models \\
\hline 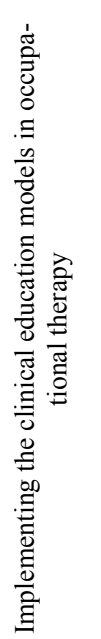 & 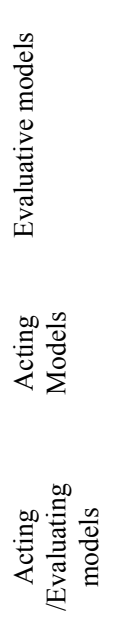 & $\begin{array}{ll}\text { - } & \text { Evaluating framework } \\
\text { - } & \text { Analyzing situations } \\
\text { - } & \text { Structure for assessing } \\
\text { - } & \text { Getting feedbacks from } \\
\text { - } & \text { strengths and weakness } \\
& \text { Strategic planning technique } \\
\text { - } & \text { Implementing frameworks } \\
\text { - } & \text { Instructional design approach } \\
& \text { Improving teaching and learn- } \\
\text { - } & \text { Evaluating and implementing } \\
\text { - } & \text { Dhase } \\
& \text { Decision about assessment } \\
& \text { and teaching method }\end{array}$ & $\begin{array}{ll}\bullet & \text { DREEM } \\
- & \text { SWOT analysis (or SWOT matrix) } \\
& \\
- & \text { (PDCA) } \\
-\quad & \text { ARCS Model of Motivational } \\
- & \text { Community Education Model } \\
- & \text { PRECEDE-PROCEED } \\
- & \text { SPICES Model }\end{array}$ \\
\hline
\end{tabular}

\section{Implementing clinical education models in occupa- tional therapy}

Fieldwork is considered as a vital part of the clinical education of students in health sciences, especially in occupational therapy, in many countries. Also, it is a professional requirement for course accreditation (14). In this study, reviewing the selected articles showed that implementing clinical education models was beneficial in several aspects: (1) improves the quality of clinical education; renews teaching strategies, enhances clinical education evaluation methods (especially fieldwork); improves relationships among students, teachers, and clients; and develops or revises curriculums $(14,15)$. In this regard, the models which have the potential for being used as clinical education models in occupational therapy include evaluative models, acting models, and evaluative/acting models. Each model can be selected based on the unique needs and purposes of clinical education settings.

\section{Evaluative models}

These models are cost-benefit evaluation models that can assist health program planners, policymakers, and trainers in improving clinical education. These models involves a wide range of areas, including the assessment of educational needs in health programs, the assessment of the needs required for better quality of life, the development and assessment of health promotion programs and other public health programs for satisfaction of those needs (16-18). These models are approved as useful tools for providing feedback on the strengths and weaknesses of different educational dimensions, such as educational environments and individuals (teachers, students, clients), in educational institutions (14).

Based on the assumptions and purposes of the Dundee Ready Educational Environment Measure (DREEM) (14) and the SWOT analysis (or the SWOT matrix) (17), these models were identified as evaluative models.

DREEM: This model has generally been accepted as a useful model for providing feedback on the strengths and weaknesses of the educational environment of educational institutions. One important advantage of the DREEM is that it provides an effective way to compare medical schools and to empower them to assess their educational status. In addition, this model may reveal students' concerns which have unintentionally been neglected by their instructors. This model is an assessment tool that evaluates 5 dimensions: teaching qualities, characteristics of teachers, involvement, affiliation, and school climate or general affect (14)

SWOT analysis (or SWOT matrix): It is a planning technique used to help people or organizations to identify their internal factors, ie, project characteristics which give them an advantage over others or put them at a disadvantage to others (17).

\section{Acting models}

These models were the models that can be used to enhance teaching quality in educational settings, especially clinical education settings. Acting models can be employed as a means of developing or revising curriculums, improving learning environments or equipment, and promoting the teaching quality of clinical educators.

The Plan-Do-Study-Act Deming circle or Shewhart cycle (PDCA) (13), the ARCS Model of Motivational Design (19), the ASSURE (20), and the Community Education Model (12) were identified as acting models.

Plan-Do-Study-Act Deming circle or Shewhart cycle (PDCA): This model is a scientific method involving all the activities relevant to quality (P: Plan, D: Do, C: Check the results, a: Act). The PDCA circulation rule is that the smaller cycle is located inside the larger cycle and protects it. These cycles reinforce each other and often interact with each other. Each time the cycle is repeated/renewed, the quality of clinical performance increases. These repetitions lead to greater quality in a spiral manner. This circle is a method frequently used by nurses for the purpose of promoting their clinical nursing quality.

Plan: Identify needs 
Do: Satisfy needs

Check: Examine the satisfaction of needs

Act: Recheck and improve performance (21).

ARCS model of motivational design: This model is appropriate for the educational designs whose focus is on the motivational aspects of learning environments. This model was proposed by John Keller in the 1980s. The model consists of 2 main parts: The first part contains 4 components of motivation: arousing interest, building relationships, developing hope for success, and gaining satisfaction through internal and external rewards (Keller 1983). The motivators in this model are teachers and educators. The second part of the model includes a process that assists teachers and educators in employing suitable motivational components for learners. In his ARCS model of motivational design, John Keller introduces 4elements: of attention, relevance, confidence, and satisfaction (ARCS) to enhance and maintain motivation in the process of learning (22)

ASSURE: The ASSURE model is an ISD (Instructional Systems Design) process that is modified to be employed by classroom teachers. This model is beneficial in aiding teachers and educators in designing and developing the most appropriate learning environment for their students. Also, it can be useful for writing lesson plans and improving teaching and learning. There are 6 phases in this model:

A- Analyze learners;

S - State standards \& objectives;

S - Select strategies, technology, media \& materials;

$\mathbf{U}$ - Use technology, media \& materials;

$\mathbf{R}$ - Require learner participation;

E - Evaluate \& revise (20).

\section{Community education model}

The community education model, also known as community-based education or community learning and development, is applicable to all individuals and groups in different communities. In fact, this model addresses group education in communities by means of a variety of formal and informal methods. It was developed for community education by Larry Horyna and Larry Decker in 1991 (23). It is based on a philosophical foundation that associates it with community education programs through 5 components of the Wisconsin community education model.

\section{Acting/evaluating models}

These models can be used both to enhance the quality of education, especially clinical education, to improve plans through detecting the weaknesses and strengths of plans via feedback and revisions based on the provided feedback.

The PRECEDE-PROCEED model (16) and the SPICES model (15) were identified as acting/evaluating models.

PRECEDE-PROCEED model: It is a cost-benefit model that can help health program planners, policymakers, and other evaluators to effectively analyze situations and treatment plans. This model provides a comprehensive framework for assessing health and quality of life needs and for designing, implementing, and evaluating health promotion programs and other public health programs for the fulfillment of these needs. One of the main goals of the PRECEDE-PROCEED model is to focus on results rather than the input. This model helps planners identify the desired outcomes. To this end, planners perform a reverse chain planning process to find successful brokers and to devise strategies based on effective goals.

The acronym of the first part of this term (PRECEDE) stands for predisposing, reinforcing and enabling constructs in educational diagnosis and evaluation. The acronym of the second part (PROCEED, which involves an ecological diagnosis) stands for policy, regulatory, and organizational constructs in educational and environmental development. This model is multidimensional and is based on social/behavioral sciences, epidemiology, administration, and education. The widespread use of this framework in RCT (randomized controlled trials) studies confirms the predictive validity of this model as a planning tool. The PRECEDE-PROCEED planning model is comprised of 4 planning stages, which include 1 implementation stage and 3 evaluation stages (24).

The PRECEDE stages are as follows: Phase 1: Social Diagnosis, Phase 2: epidemiological, behavioral, and environmental diagnosis, Phase 3: educational and ecological diagnosis, Phase 4: administrative and political diagnosis. The PROCEED stages are as follow: Phase 5: implementation, Phase 6: process evaluation, Phase 7: impact assessment, Phase 8: assessment of results.

The PRECEDE-PROCEED model is a collaborative model to promote community health and enhance other public health interventions. It is assumed behavior change is voluntary and health programs are effective if they are implemented, planned, and evaluated with the active participation of those who are involved in implementing them and those who are affected by them. Therefore, it scrutinizes health and other related issues within communities.

\section{SPICES model}

This model contains 6 curriculum features worth considering by teachers and instructors in medical schools:

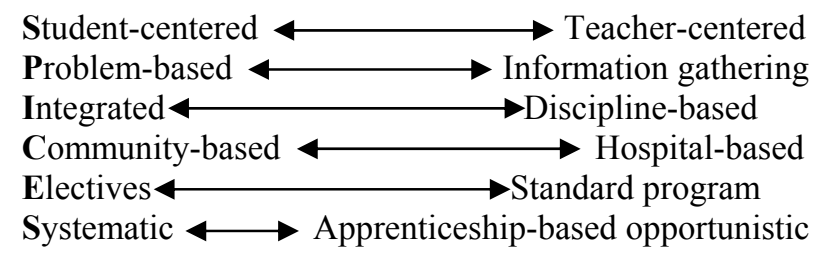

The features on the left side associate with the innovative plans (SPICES) and those on the right side pertain to the traditional plans. The features are interrelated and any decision on one feature clearly affects the other. This model can be used as a means of reviewing stimulating curriculums, developing new curriculums, tackling specific questions or issues related to curriculums, and making better decisions on teaching and assessment methods (25). 


\section{Discussion}

The findings obtained from reviewing the 8 clinical education models showed that the mentioned models in clinical education can help educators, students, and educational planners in different fields of study. Among these 8 models, 2 have the required structure and framework for evaluation and were categorized as evaluative models. Four models provide a framework for clinical education in different contexts and for plan-making processes to make modifications to clinical education and promote its quality. These models were categorized as acting models. The PRECEDE-PROCEED and SPICES models were the only models that can be used both to enhance the quality of clinical education and to evaluate the weaknesses and strengths of health promotion programs.

In this study, the Dundee Ready Educational Environment Measure (DREEM) (14) and the SWOT analysis (or SWOT matrix) (17) were identified as evaluative models. Among these models, the DREEM does not consider students as a dynamic and productive factor in the clinical education process. In addition, this model assumes that it evaluate any particular clinical education is not required and the main emphasis is placed on clinical education environments (16). By conducting an in-depth assessment and identifying strengths and weaknesses as well as opportunities and behaviors, the SWOT analysis can help to improve the quality of education to a great extent (17).

The Plan-Do-Study-Act Deming circle or Shewhart cycle (PDCA) (13), the ARCS model of motivational design (19), the ASSURE (20), and the Community Education Model (23) were identified as acting models. The PDCA is a general model that can be used in a wide range of areas, including management and education. This model suggests that the initial phase in any project, including clinical education, is to take 4 steps: plan, do, study, and act. The major purpose of this model is to increase the quality of services, including educational services, especially those of clinical education, and to provide services with higher quality to advance the goals of education (13).

The ARCS model of motivational design underscores the motivational factors governing educational environments. Its main emphasis is put on providing educational systems with learning environments that have many motivational factors to improve learning (19). Motivational factors only include environmental factors, and other dynamic factors, such as trainers' characteristics and students are ignored (19).

The ASSURE model is performed by a trainer in an educational environment. In this model, trainers collaborate with students to design and prepare suitable educational and training environments before the education process. One of the main goals of this model is to promote the use of advanced educational technologies in educational environments (20).

The main philosophy behind the development of the community education model is group learning (12). This model is useful and effective when the student is learning from a group of educators and classmates. This model has potential applications for group trainings whose major aim is to learn from each other (12). This model is such effective in teaching clients that in their study, Kate E. et al recommended occupational therapists using it for client education (12). The PRECEDE-PROCEED (16) and SPICES (23) models were identified as acting/evaluating models.

In addition to assessing the individuals involved in clinical education (students and instructors), the PRECEDEPROCEED model evaluates the environment of clinical education (16). This model provides a particular framework for evaluating environments and individuals, which is considered as its strong point. However, one disadvantage of this model is its failure to introduce any particular clinical teaching method. Moreover, it does not differentiate between various contexts of clinical education (hospital, clinic) and it uses the same evaluation framework for all situations and environments (16).

In this regard, the SPICES model suggests that the developed curriculums, educational methods and assessment tools should be: student-centered, problem-based, integrated, community-based and electives (15). The SPICES model can be used to update educational systems and keep up with the educational systems of developed countries. (15).

\section{Conclusion}

The results of this study showed that occupational therapists can employ the above-mentioned models as clinical education models for clinical education in occupational therapy settings. Each model has its own advantages and disadvantages and can be selected based on the purposes of clinical educators.

The mentioned models can be used with the aim of enhancing teaching quality in educational contexts, especially the quality of occupational therapy in clinical education settings. Although confirming the utility of these models requires further research in occupational therapy fieldwork settings, occupational therapy clinical educators should pay attention to these models and employ them directly or indirectly to enhance their ability in clinical education.

\section{Suggestion}

The authors suggest that occupational therapists develop a clinical education model that can particularly be used for clinical education in occupational therapy settings.

\section{Conflict of Interests}

The authors declare that they have no competing interests.

\section{References}

1. Rezaee M, Rassafiani M, Khankeh H, Hosseini MA. Experiences of occupational therapy students in the first fieldwork education: a qualitative study. Med J Islam Repub Iran. 2014;28:110-5.

2. Khalifehzadeh A, Tavasoli AA, Golshahi J, Sanei H, Mirdehghan A, Paydar Z, et al. Synergy Model in Clinical Teaching of Critical Care MSc Nursing Students and Cardiovascular Diseases Patients. Iran J Med. 2011;10:593-601.

3. Pashmdarfard M, Shafaroodi N. Factors affecting the clinical education of rehabilitation students in Iran: A systematic review. Med J Islam Repub Iran. 2018;18(32):1-8. 
4. Latifi M, Shaban M, Nasrabadi AN, Mehran A, Yekta ZP. Effect of clinical evaluation with portfolio on critical thinking skills of nursing students. Iran J Med. 2011;11:368-81.

5. Abotalebi G, Vosoghi N, Sajadi A, Nejad EM, Akbary M. Evaluation of clinical education from the perspective of nursing students of Ardabil University of Medical Sciences in 2009. J Health. 2010;1(1):31-7.

6. Elcigil A, Sari HY. Determining problems experienced by student nurses in their work with clinical educators in turkey. Nurse Edu Today. 2007;5:491-8.

7. Oermann M. Developing a professional portfolio in nursing. Orthop Nurs. 2002;21(2):73-8.

8. Arksey H, O'Malley L. Scoping studies: Towards a methodological framework. Int J Soc Res Methodol. 2005;8:19-32.

9. Conn A, Bourke N, James C, Haracz K. Occupational therapy intervention addressing weight gain and obesity in people with severe mental illness: A scoping review. Aust Occup Ther J. 2019.

10. Moher D, Liberati A, Tetzlaff J, Altman D. Preferred Reporting Items for Systematic Reviews and Meta-Analyses: The PRISMA Statement. PLoS Med. 2009;6(7).

11. Braun V, Clarke V. Using thematic analysis in psychology. Qual Res Psychol. 2006;3:77-101.

12. DeCleene KE, Ridgway AJ, Bednarski J, Breeden L, Mosier GG, Sachs D, et al. Therapists as Educators: the Importance of Client Education in Occupational Therapy. Open J Occup Ther. 2013;1(4).

13. Taylor M, McNicholas C, Nicolay C, Darzi A, Bell D, Reed JE. Systematic review of the application of the plan-do-study-act method to improve quality in healthcare. BMJ Qual Saf. 2014;23:290-8.

14. Brown $\mathrm{T}$, Williams $\mathrm{B}$, Lynch $\mathrm{M}$. The Australian DREEM: evaluating student perceptions of academic learning environments within eight health science courses. Int J Med Educ. 2011;2(94).

15. Sathaananthan T. Harden's Spices Model for Biochemistry in Medical Curriculum. Int J Health Life Sci. 2017;3(1):95-104.

16. Morris DM, Jenkins GR. Preparing Physical and Occupational Therapists to Be Health Promotion Practitioners: A Call for Action. Int J Environ Res Public Health. 2018;15(392):1-12.

17. Camden C, Swaine B, Tétreault S, Bergeron S. SWOT analysis of a pediatric rehabilitation programme: A participatory evaluation fostering quality improvement. Disabil Rehabil. 2009;31(16):1373-81.

18. Torabipour A, Sayaf R, Salehi R, Ghasemzadehdoi R. Analyzing the Quality Gapsin the Services of Rehabilitation Centers Using the SERVQUAL Technique in Ahvaz, Iran. Jundishapur J Health Sci. 2016;8(1):25-30.

19. Wongwiwatthananukit S, Popovich N. Applying the ARCS Model of Motivational Design to Pharmaceutical Education: statement. Am J Pharm Educ. 2000;64:188-96.

20. Goode P. Using the ASSURE Model and Gagne's 9 Events of Instructions as a Teaching Strategy. Nurse Educr. 2018;43(4):159-73.

21. MA L, Hu X, Hao C, Liu F, Tian T. Impacts of PDCA circle's clinical nursing path on the postoperative recovery and life quality of gastric patients. Int J Clin Exp Med. 2017;10(2):3669-76.

22. Keller J. Motivational design for learning and performance: The ARCS model approach. United State: Springer US; 2010.

23. Hill N, Castellino D, Lansford JE, Nowlin P, Dodge K, Bates J, et al. Parent Academic Involvement as Related to School Behavior, Achievement, and Aspirations: Demographic Variations Across Adolescence. Child Dev. 2004;75(5):1491-509.

24. Green L. Toward cost-benefit evaluations of health education: some concepts, methods, and examples. Health Educ Monogr. 1974;2(2):34-64.

25. Harden RM, Soweden S, Dunn WR. Educational strategies in curriculum development: the SPICES model. Med Educ. 1984;18(4):284-97. 